\title{
Kajian Potensi Air Pengerak Pompa Hidram Untuk Mengairi Sawah Di Daerah Pakandangan Kabupaten Padang Pariaman
}

\author{
Study Of Hidram Pump Driver Water PotentialTo Irrigate Sawah In \\ Pakandangan Region, Padang Pariaman Regency
}

\author{
Ichlas Nur, Nota Effiandi, Mulyadi, Maimuzar \& Hendra \\ Jurusan Teknik Mesin Politeknik Negeri Padang Kampus Limau Manis Padang \\ Telp.0751-72590 Fax. 0751-72576 Email: ichlas nur@ gmail.com
}

\begin{abstract}
Energy is needed in mobilizing a mechanism both electric energy and energy derived from fossils. Hydram pump is a device to raise water from a low place to a high place by utilizing water impacts without using renewable energy. In Pakandangan, Padang Pariaman Regency, there is a water source that cannot be utilized to flow through the rice fields around $10 \mathrm{Ha}$. Because the rice fields are higher with water sources. The methodology is to survey the location and design the dimensions of the hydram pump. The results obtained head data height of incoming water is 2.5 meters, the height of water lift to the shelter is 7 meters the flow of water entering the pump is $25 \mathrm{lt} / \mathrm{sec}$. The dimensions of the pump are the result of the design of a hydram 1 size with an inside diameter of 2 inches
\end{abstract}

Keyword : hydram pump, rewenable, energy,rice

\section{PENDAHULUAN}

Pakandangan - Pusat Pengembangan dan Pembangunan Desa-Nagari (P3D) Politeknik Negeri Padang (PNP) sebagai lembaga yang menjembatani kebutuhan nagari dengan potensi-potensi yang dimiliki oleh PNP dalam berkontribusi ke DesaNagari terus berupaya untuk mencarikan solusi terhadap berbagai permasalahan yang muncul di Nagari yang bermanfaat untuk masyarakat.

Salah satu Nagari binaan PNP, Nagari Pakandangan Kec. Enam Lingkung Kab. Padang Pariaman, saat ini dalam proses mewujudkan Program Nagari Digital dari P3D PNP.Nagari Pakandangan memiliki lahan pertanian yang sangat luas, yaitu sawah tadah hujan. Diperkirakan hampir $70 \%$ nagari ini merupakan lahan pertanian. Dalam pertemuan dengan ketua Teknologi Tepat Guna nagari Pakandangan, Bpk. Ikram, beliau menyampaikan bahwa lahan pertanian kami yang luas ini merupakan sawah tadah hujan, sehingga kuantitas pertanian kami sangat tergantung kepada Hujan, sementara potensi air dan irigasi sudah ada, namun lokasinya berada di bawah lahan pertanian ini, yang berjarak sekitar 6-8 m, sehingga saluran irigasi dan potensi air yang sangat besar belum termanfaatkan dengan baik. Kami telah mencoba berbagai alternatif, namun belum maksimal [Warta P3M 2019 Politeknik Negeri Padang]. Alternatif yang dilakukan saat ini adalah memanfaatkan kincir air untuk memutar generator listrik yang dihasilkan untuk mengerakkan pompa air dapat dilihat pada gambar 1. Pemanfaatan lahan untuk pertanian di daerah Pakandangan dapat meningkatkan penghasilan penduduk. Agar lahan tersebut dapat di manfaatkan untuk pertanian tersebut maka diperlukan irigasi atau aliran air yang terus menerus selama 24 jam. Permasalahan yang terjadi adalah lahan yang akan dialiri lebih tinggi dari dari artinya sumber air lebih rendah dari lahan pertanian yang akan dialiri. Maka diperlukan suatu mesin yang dapat membantu menaikkan air 
tersebut ke persawahan tanpa mengunakan sumber fosil. Mesin yang dicocok digunakan alat Pompa Hidram. . Teknologi pompa hidram ini sangat murah dan dapat dikembangkan, terlebih bagi daerah-daerah perdesaan dan pedalaman yang tidak memiliki potensi sumber daya air atau tidak dilewati aliran sungai [Leonardo, 20012]. Teknologi pompa hidram menggunakan tekanan air yang mengalir karena perbedaan tinggi dan tekanan hidrolik untuk menaikkan air ke tempat yang lebih tinggi. Dengan teknologi ini, sumber mata air yang letaknya jauh atau berada di lembah yang terjadi bisa menjadi berkah bagi desa yang letaknya jauh sekalipun.

Pompa hidram tidak memerlukan tenaga listrik atau bahan bakar apapun. Pompa hidram yang telah dimodifikasi mampu mengangkat air sampai ketinggian vertikal 50-80 meter (head) dan mampu mengantar air sampai jarak dua kilometer pada keadaan ideal. Debit air pada head 3050 meter sebesar 30 liter/menit mampu melayani penduduk satu buah desa. Keunggulan teknologi ini, yaitu mempunyai head (daya angkat air vertikal) berkisar 5080 meter sehingga mampu menaikkan air bersih dari sumber mata air yang terletak di jurang terjal. Biaya perakitan hidram relatif murah dengan umur teknis 25 tahun. Biaya perawatan komponen relatif murah yaitu hanya mengganti klep katup limbah dan klep kupu-kupu yang terbuat dari ban bekas setiap dua tahun sekali. Pompa hidram dapat diterapkan di kawasan pelosok yang membutuhkan pompa untuk menaikkan air, namun belum terjangkau aliran listrik,. Teknologi seperti ini sangat dimungkinkan untuk mensupport sektor pertanian dalam arti luas yang saat ini tengah dikembangkan oleh daerah-daerah yang tidak memiliki potensi irigasi pertanian dapat mengadopsi inovasi teknologi pompa hidram, sehingga kebutuhan pengairan untuk sawah dapat terpenuhi. Dengan adanya penelitian ini Politeknik Negeri Padang khususnya prodi Teknik Mesin dapat memberikan kontribusi ke masyarakat dengan pengembangan bidang energy terbarukan. Publikasi ilmiah yang dihasilkan dapat menjadi acuan untuk pengembangan lebih lanjut dibidang penelitian yang sejenis.

Mengutip dari Surat kabar Pemprov Propinsi Kaltim tertanggal 12 September 2013 Pelaksana Tugas Sekprov Kaltim Dr $\mathrm{H}$ Rusmadi menyatakan ketertarikannya untuk mengadopsi inovasi teknologi pompa hidram tenaga air melalui sistem balon pada katup tabung untuk sistem pengairan pertanian di Kaltim maupun dalam upaya pemenuhan kebutuhan air bersih di daerah pedalaman yang belum terjangkau listrik.

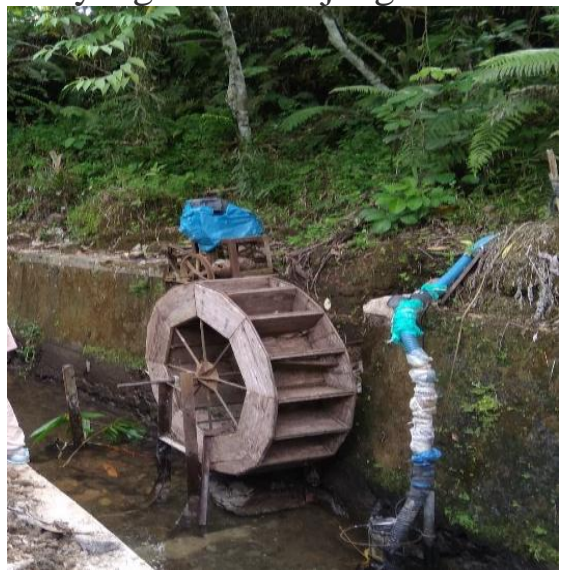

Gambar 1. Pemanfaatan kincir air untuk memutar generator untuk mengerakkan pompa

Inovasi teknologi tersebut merupakan hasil karya dari Sudianto, warga Desa Kotayasa, Kecamatan Sumbang Kabupaten Banyumas Jawa Tengah yang berhasil mendapatkan Anugerah Kreativitas dan Inovasi Masyarakat (Labdhakretya) pada puncak peringatan Hari Kebangkitan Teknologi Nasional (Hakteknas) ke-18 di Jakarta belum lama ini. Pompa Hidram, berasal dari kata Hydraulic Ram Pump, yang berarti pompa yang memanfaatkan tenaga hantaman air. Di Indonesia pompa ini sebenarnya sudah ada sejak jaman penjajahan Belanda, namun kurangnya perawatan dan pengetahuan untuk membuat pompa ini tidak berkembang dengan baik. Prinsip kerja Hidram adalah pemanfaatan gravitasi dimana akan menciptakan energi dari hantaman air yang menabrak faksi air lainnya untuk mendorong ke tempat yang lebih tinggi tanpa memerlukan energy pengerak dari energy fosil. Untuk 
mendapatkan energi potensial dari hantaman air diperlukan syarat utama yaitu harus ada terjunan air yang dialirkan melalui pipa dengan beda tinggi elevasi dengan pompa Hidram minimal 1 meter. Jadi teknologi pompa hidram adalah solusi yang tepat.

Syarat utama kedua adalah sumber air harus kontunyu dengan debit minimal 7 liter per menit (Widarto, 2000). Besarnya debit pemompaan dapat dihitung dengan rumus Q2 = Q1 x H1 : H2 x j. Dimana Q2 adalah debit air yang dipompakan (liter/menit), Q1 adalah debit air yang masuk pompa (liter/menit), H1 adalah tinggi terjunan dalam meter, $\mathrm{H} 2$ adalah tinggi pemompaan dalam meter dan $\mathrm{j}$ adalah efisiensi pompa yaitu 0,5 -0,75. Dalam prakteknya diperoleh perbandingan tinggi terjunan dan tinggi pengangkatan air sebesar 1:6, akan menghasilkan debit pemompaan sebesar $1 / 3$ dari debit air yang masuk ke pompa, sedang $2 / 3$ debit air akan keluar melalui klep pembuangan setelah memberikan tenaga hantaman.

\section{Cara Kerja Pompa Hidram}

Cara kerja pompa hidram terbagi dalam 4 siklus, untuk lebih jelasnya dapat dilihat pada tabel di bawah ini [4] :

Tabel 1. Cara Kerja Pompa Hidram

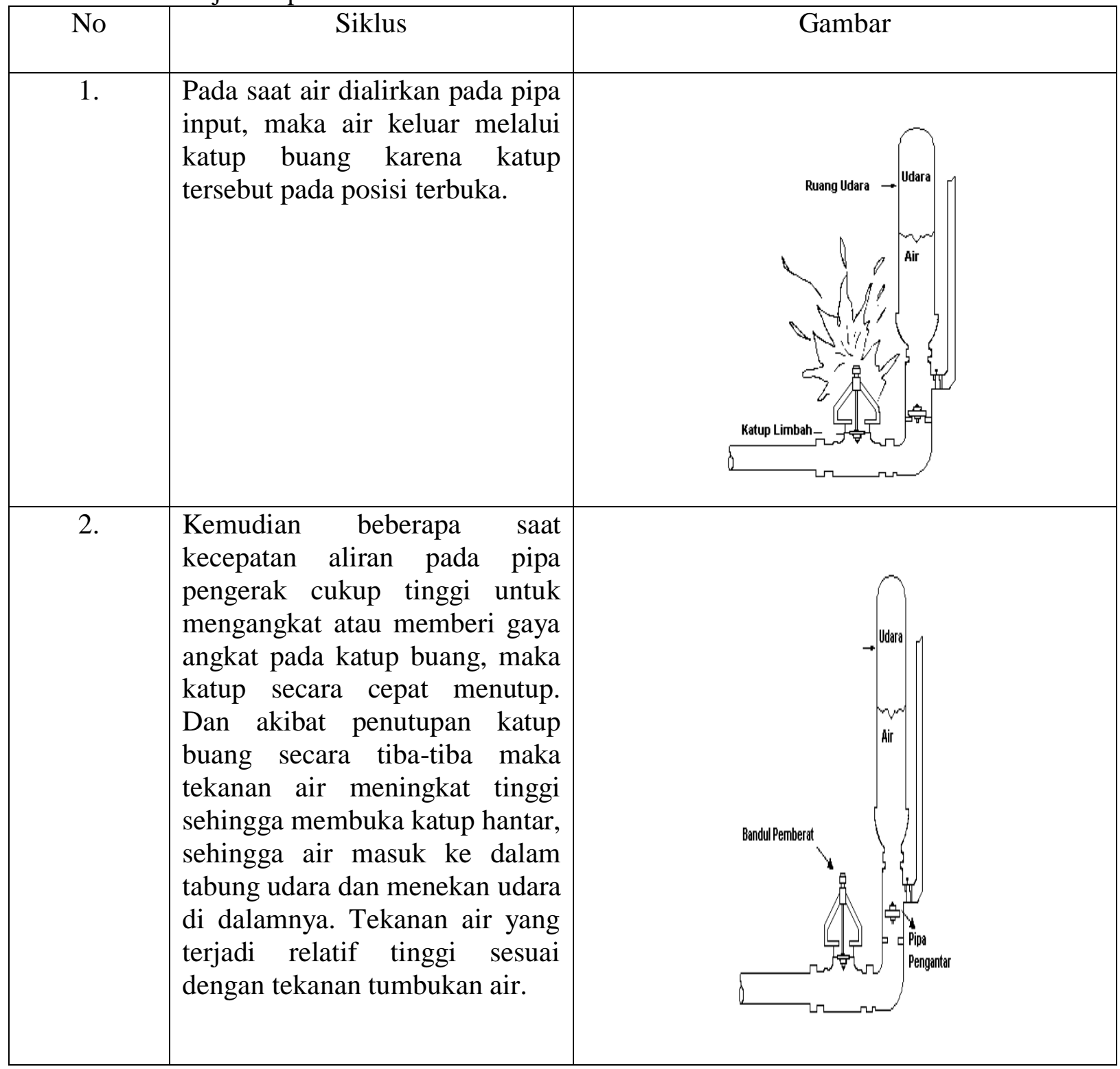




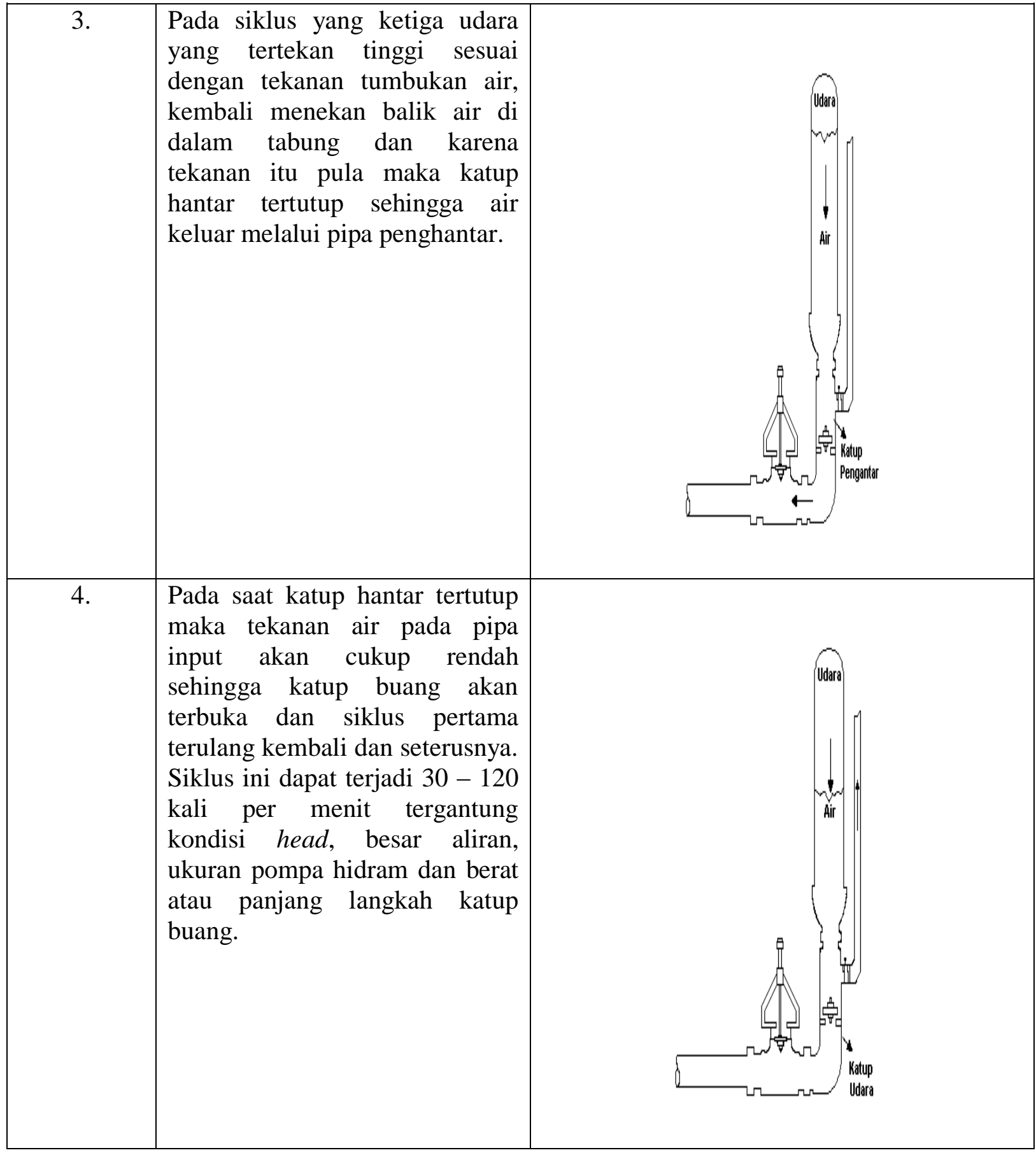

\section{Karakteristik Pompa Hidram}

Karakteristik pompa hidrolik ram atau hidram yang bekerja pada keadaan tertentu, Pompa yang terbuat dari bahan besi cor yang kuat dapat bekerja dengan baik hingga bertahun-tahun. Hal ini merupakan penghematan investasi yang luar biasa bagi kelompok petani. Ukuran pompa hidram ditentukan oleh kapasitas yang dikehendaki dan juga dibatasi oleh jumlah air yang tersedia untuk menggerakkan pompa. Pompa harus dipasang serata mungkin untuk meyakinkan bahwa katup limbah yang diberi beban dapat jatuh tegak lurus ke bawah dengan gesekan sekecil mungkin. Pemasangan pipa juga harus diperhatikan agar tidak ada belokan-belokan tajam atau sudut yang mengurangi kekuatan aliran air. Beberapa hasil eksperimen juga menunjukkan bahwa adanya ruang udara pada pompa hidram semakin meningkatkan efisiensi pompa dalam mengalirkan air ke tempat yang lebih tinggi. 
Secara spesifik, menurut Direktorat Pengelolaan Air Departemen Pertanian, daerah yang bisa memanfaatkan teknologi irigasi Pompa Hidram adalah memiliki ciri sebagai berikut :

1. Merupakan daerah sentra produksi pertanian yang memiliki potensi luas lahan untuk dijadikan sebagai lahan pertanian beririgasi.

2. Di sekitar lokasi pengembangan, terdapat sumber air permukaan seperti sungai dengan jumlah dan kualitas air yang memadai, terutama pada musim kemarau.

3. Di lokasi pengembangan terdapat kelompok tani yang aktif.

4. Lokasi merupakan lahan milik petani dan sekaligus penggarap.

5. Penentuan/penetapan lokasi berdasarkan kesepakatan kelompok dan tidak menuntut ganti rugi atas pemanfaatan lahan.

Syarat tersebut dimaksudkan agar sistem irigasi tersebut dapat digunakan dan terpelihara dalam jangka panjang. Jika suatu daerah sudah memenuhi syarat umum tersebut, maka pembangunan sistem irigasi dengan menggunakan pompa hidram bisa dimulai.

\section{METODOLOGI}

Metode penelitian yang digunakan pada penelitian ini adalah merancang dimensi pompa hidram. Penelitian ini dilaksanakan tiga tahap yaitu kajian pustaka, survey lokasi ke daerah pakandangan, dan desain pompa hidram rekayasa dilakukan di Politeknik Negeri Padang

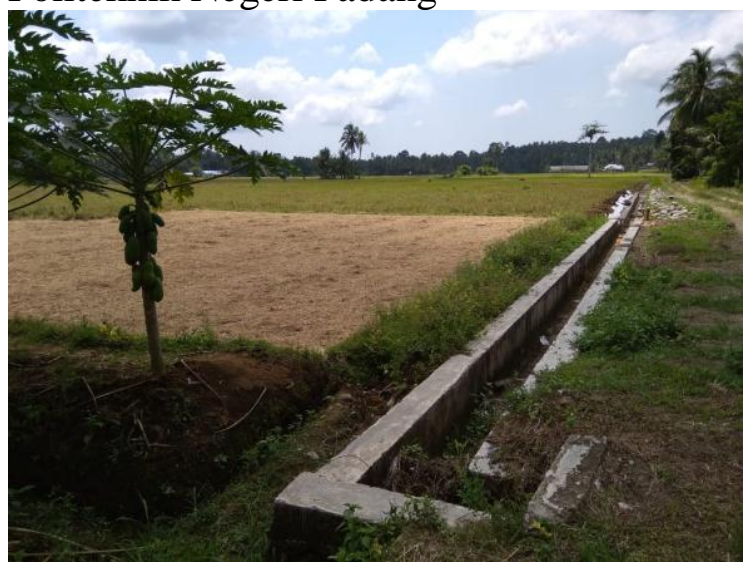

Gambar 2. Lokasi sawah yang akan dialiri

\section{HASIL DAN PEMBAHASAN Hasil Survey yang telah dilakukan}

Setelah melakukan survey luas daerah yang akan dialiri air seluas $\pm 10 \mathrm{Ha}$ dapat dilihat pada gambar 2 serta lokasi sumber air yang tersedia dapat dilihat pada gambar 3 maka didapat debit air sungai 25 1t/dt. Di daerah Pakandangan Kecamatan Enam Lingkung Kabupaten Padang Pariaman, berupa teknologi produk pompa Hidram untuk menaikkan air setinggi $\mathrm{h} 2=7$ meter mengairi lahan pertanian atau daerah pelayanan $10 \mathrm{Ha}$ dengan tinggi jatuh ke air ke pompa $\mathrm{h} 1=2.5$ meter, jarak L2 $=40$ meter dan L1= 28 meter. Dapat dilihat pada gambar 4.

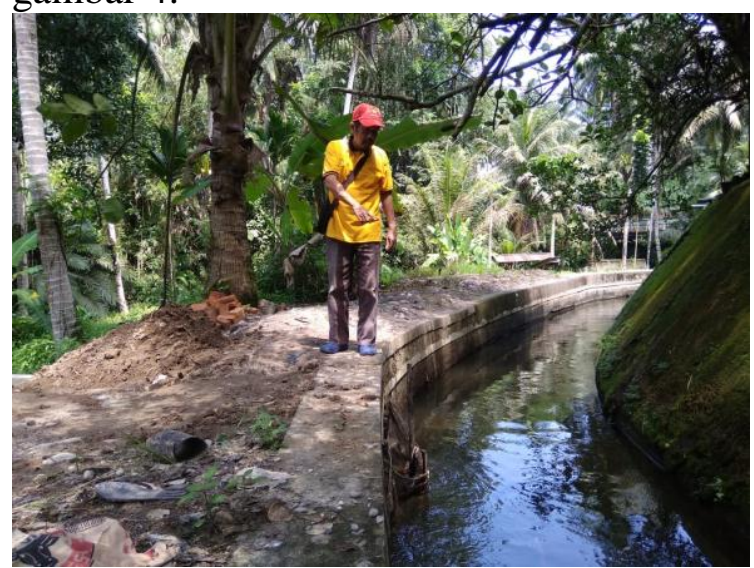

Gambar 3. Sumber air untuk pompa hidram

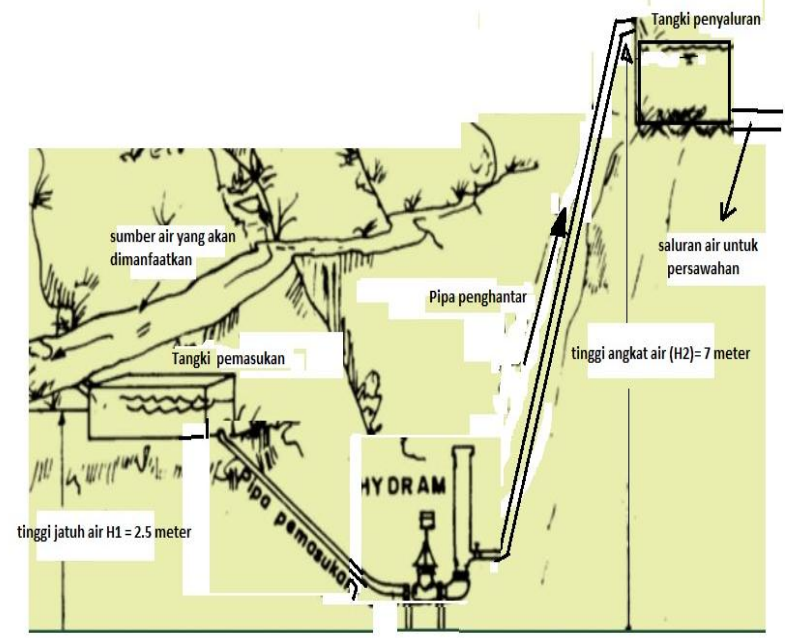

Gambar 4. Lokasi rancangan tempat pompa hidram

\section{Rancangan Pompa Hidram}

Setelah diperoleh data lokasi tentang debit sumber air, perbedaan ketinggian dan 
daerah pemanfaatan, maka kita dapat

menghitung Dimensi pompa hidram yang

direncanakan adalah

Menghitung jumlah aliran pengeluaran dengan rumus

Q2(output) /hari $=\frac{\text { Tinggi jatuh vertikal } x \text { aliran sumber } x \text { rendemen }}{\text { daya angkat vertikal }}$

$$
\text { atau } Q_{2}=\frac{H_{1} x Q_{1} x r}{h_{2}}
$$

Keterangan :

$\mathrm{Q}_{1}=$ jumlah kebutuhan air yang diperlukan
$\mathrm{Q}_{2}=$ debit air yang masuk pompa

$\mathrm{H}_{1}=$ beda jatuh vertical

$\mathrm{H} 2=$ beda tinggi/daya angkat vertikal

$r=$ rendemen $(0.5-0.6)$

1. Menghitung jumlah aliran pemasukan dengan rumus

$$
\begin{aligned}
& \text { atau } Q_{2}=\frac{H_{1} x Q_{1} x r}{h_{2}} \\
& \text { didapat } \mathrm{Q}_{1}=17.85 \mathrm{lt} / \mathrm{dt}
\end{aligned}
$$

dari perhitungan diatas dapat dibuat pompa hidram dengan rancangan menurut tabel

\begin{tabular}{|c|c|c|c|c|c|c|c|}
\hline $\begin{array}{l}\text { Ukuran } \\
\text { hidram }\end{array}$ & & 1 & 2 & 3 & 4 & 5 & 6 \\
\hline Diameter & $\mathrm{mm}$ & 32 & 38 & 51 & 76 & 101 & 127 \\
\hline dalam & Inci & $11 / 4$ & $11 / 2$ & 2 & 3 & 4 & 5 \\
\hline $\begin{array}{l}\text { Debit } \\
\text { pompa }\end{array}$ & dari & 7 & 12 & 27 & 68 & 132 & 180 \\
\hline $\begin{array}{l}\text { (Qs). } \\
\text { (L/menit) }\end{array}$ & ke $x$ ) & 16 & 25 & 55 & 137 & 270 & 410 \\
\hline
\end{tabular}
berikut :

Tabel 1. kapasitas pompa menurut Watt,1974

2. Ukuran pompa hidram ditentukan berdasarkan ukuran diameter dalam pipa masukan.

Tabel 2. Tipe Berdasarkan Penelitian ITB

\begin{tabular}{|c|c|c|}
\hline TYPE & $\begin{array}{c}\text { Garis tengah } \\
\text { diameter dalam } \\
\text { pipa pemasukan } \\
\text { (inch) }\end{array}$ & $\begin{array}{c}\text { Garis tengah } \\
\text { diameter dalam } \\
\text { pipa pengeluaran } \\
\text { (inch) }\end{array}$ \\
\hline 1 & 1.50 & 0.75 \\
\hline 2 & 2.00 & 1.00 \\
\hline 3 & 3.00 & 1.50 \\
\hline 4 & 4.00 & 2.00 \\
\hline 5 & 5.00 & 3.00 \\
\hline
\end{tabular}

Tabel 3. Jumlah kebutuhan air maksimum menurut "Silver 1977"

\begin{tabular}{|c|c|c|c|}
\hline \multicolumn{2}{|c|}{ Badan Pompa } & \multirow{2}{*}{$\begin{array}{c}\text { Pemasukan } \\
\text { minimum }\end{array}$} & $\begin{array}{c}\text { Pemasukan } \\
\text { maksimum } \\
\text { (It/menit) }\end{array}$ \\
\cline { 1 - 2 } (inch) & (mm) & (It/menit) & $\mathbf{3 7 . 9}$ \\
\hline 1.00 & $\mathbf{2 5}$ & $\mathbf{7 . 6}$ & 56.8 \\
\hline 1.50 & 37 & 17.1 & 94.6 \\
\hline 2.00 & 51 & 30.3 & 151.4 \\
\hline 2.50 & 63.5 & 56.8 & 265 \\
\hline 3.00 & 76 & 94.6 & 378.5 \\
\hline 4.00 & 102 & 151.4 & \\
\hline
\end{tabular}


Tabel 4. Nama komponen pompa

\begin{tabular}{|c|l|c|}
\hline TEM & \multicolumn{1}{|c|}{$\begin{array}{c}\text { KOMPONEN POMPA } \\
\text { HIDRAM }\end{array}$} & $\begin{array}{c}\text { JUM } \\
\text { LAH }\end{array}$ \\
\hline 1 & Body & 1 \\
\hline 2 & Katup Karet Limbah & 1 \\
\hline 3 & Katup Limbah & 2 \\
\hline 4 & Rangka & 1 \\
\hline 5 & DIN 6923 - M10 & 24 \\
\hline 6 & Karet Katup Penghantar 1 & 1 \\
\hline 7 & Tabung Udara & 1 \\
\hline 8 & Katup Penghantar & 1 \\
\hline 9 & Pressure Gauge 0 - 6 Bar & 1 \\
\hline 10 & $\begin{array}{l}\text { ANSI B18.2.3.4M - M10 x } \\
0.8 \text { x 30 }\end{array}$ & 16 \\
\hline 11 & $\begin{array}{l}\text { ANSI B18.2.3.4M - M10 x } \\
0.8 \text { x 35 }\end{array}$ & 6 \\
\hline 12 & Dudukan Katup Limbah & 1 \\
\hline 13 & $\begin{array}{l}\text { ANSI B18.2.3.4M - M10 x } \\
0.8 \times \text { 40 }\end{array}$ & 8 \\
\hline 14 & Karet Katup Penghantar 2 & 1 \\
\hline 15 & Pemberat / Beban & 1 \\
\hline
\end{tabular}

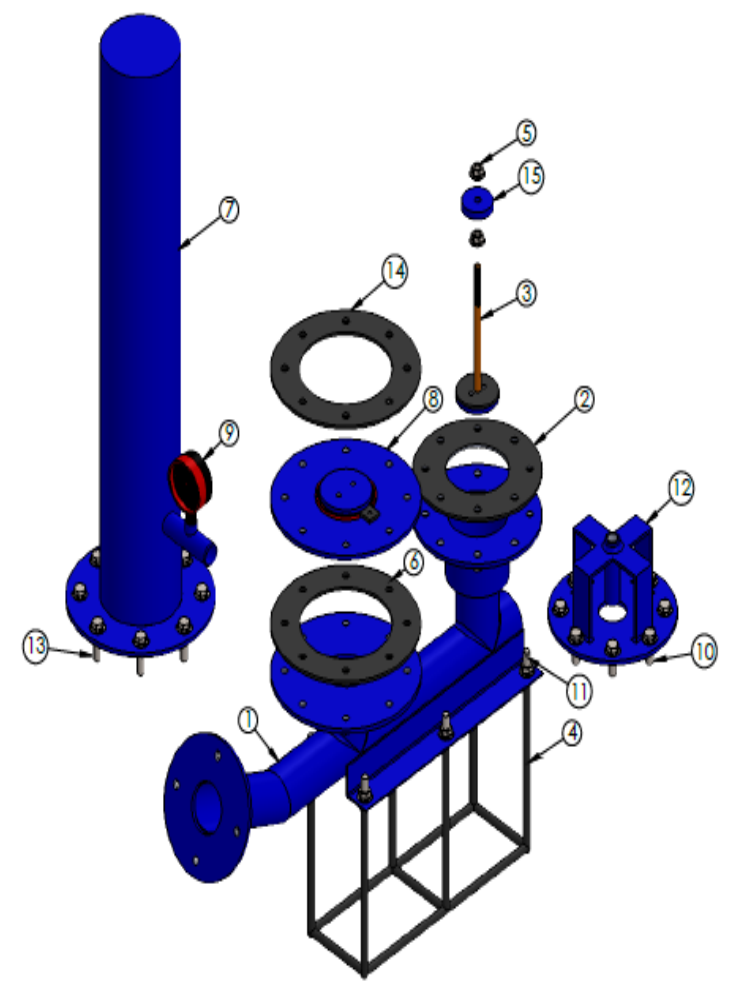

Gambar 5. Hasil rancangan Komponen Pompa Hidram
3. Perawatan Pompa Hidram

Adapun perawatan yang dilakukan pada pompa hidram adalah

a) Air yang mengalir ke pipa masuk pompa hidram harus di upayakan air yang bersih sehingga mengurangi ganguan kinerja pompa hidram.

b) Perlu di upayakan dalam menggunakan pompa hidram di perlukan adanya bak penyaring yang berfungsi untuk menyaring kotoran ranting ,daun atau sejenisnya tidak masuk kedalam pompa.

c) Pompa hidram tidak memerlukan perawatan yang rumit, bila kerja pompa tidak berjalan maka di perlukan pengamatan dari mana pompa tidak bekerja, hal ini bisa di sebabkan karena sumber air sebagai penggerak pompa berkurang atau bisa juga karena masuknya kotoran yang mengganjal katup pompa, bila ini terjadi di perlukan pembongkaran pompa untuk membersihkan.

\section{SIMPULAN}

Berdasarkan survey dan rancangan , maka dapat disimpulkan sebagai berikut :

1. Beda tinggi jatuh vertikal adalah 2.5 meter, daya angkat vertikal $=7$ meter, debit air yang masuk pompa adalah 25 lt/dt dan debit keluar pompa 17,8 lt/dt

2. Ukuran Hidram adalah 1, untuk diameter dalam $38 \mathrm{~mm}$ atau 1.5 inch.

\section{SARAN}

1. Pompa Hidram harus dipasang lebih dari satu untuk memenuhi kebutuhan air sawah yang memadai

2. Untuk memenuhi kebutuhan irigasi maka diperlukan lebih dari satu pompa hidram

\section{UCAPAN TERIMA KASIH}

Terima kasih kepada DIPA dan Politeknik Negeri Padang yang telah mendanai kegiatan penelitian ini melalui dana penelitian BOPTN Politeknik Negeri Padang dengan no. kontrak 357 / PL9. 1.4 / PT.01.02/2019. 


\section{DAFTAR PUSTAKA}

Leonardo, El.. (2002). Design and Construction of a Hydraulic Ram Pump. Universitas of Nigeria. Nigeria.

Made Suarda dan IKG Wirawan. 2008. Kajian Eksperimental Pengaruh Tabung Udara pada Head Tekanan Pompa Hidram. Jurnal Teknik Mesin Cakram. $10-14$.

Santoso. 2005. Pemanfaatan Tenaga Air. Jakarta. LIPI.

Sularso, dan Haruo Tahara. 1997. Pompa dan Kompresor, Pemilihan, Pemakaian dan Pemeliharaan. Pradnya Pramita. Jakarta.

Widarto, L. \& FX. Sudarto C. Ph. (2000). Teknologi Tepat Guna: Membuat Pompa Hidram. Kanisius. Yogyakarta.

Budiman Agus,dkk, Pelatihan pembuatan Hidram sebagai Alternatif Penghematan Tenaga Listrik dan Pemenuhan kebutuhan Air pada Musim kemarau, LPPM Universitas Negeri Yogyakarta, 2010

MT., Meylani Setyawaty Meylani Lya, Ir , Pemanfaatan Pompa Hidram Dalam Penyedian Air Bersih, Pusat Penelitian dan Pengembangan Pemukiman Balitbang Kementrian Pekerjaan Umum, 2014

Warta P3M Politeknik Negeri Padang, 2019 Surat Kabar Pemprov Kaltim, 2013 